\title{
Retóricas de la distinción en la crónica latinoamericana
}

\section{Rhetorics of the Distinction in the Latin American Chronicle}

\author{
Julieta Viú Adagio*
}

RESUMEN: este artículo se propone trazar un mapa de la crónica latinoamericana moderna e iluminar una serie de hitos artísticos y culturales que signaron su historia. Con el objetivo de identificar y periodizar los intereses hegemónicos de los escritores en relación con el campo cultural y las lecturas teóricas generales del arte y la literatura. Estos análisis permitieron identificar el auge del divismo modernista caracterizado, entre otras cuestiones, por la reivindicación de la aristocracia del arte; la celebridad basada en una retórica de la fama; y en oposición a éstos la emergencia de la plebeyez que ubica en el centro de la representación a personajes populares. La originalidad de este trabajo reside en la lectura del campo de la crónica cuya tradición de estudios en general ha avanzado por autores apreciados individualmente. De igual importancia en cuanto a su originalidad es el haber identificado los tópicos descritos, desconsiderados por el campo de la crítica.

\section{Palabras Clave: Crónica latinoamericana; Modernismo; Célebre; Plebeyo.}

ABSTRACT: This article aims to draw a map of the modern Latin American chronicle and illuminate a series of artistic and cultural milestones that marked its history. With the aim of identifying and periodizing the hegemonic interests of writers in relation to the cultural field and the general theoretical readings of art and literature. These analyzes allowed us to identify the rise of the modernist divism characterized, among other issues, by the claim of the aristocracy of art; the celebrity based on a rhetoric of fame; and in opposition to these the emergence of the plebeyez that locates popular characters in the center of the representation. The originality of this work lies in the reading of the field of the chronicle whose tradition of studies in general has advanced by authors appreciated individually. Of equal importance in the originality of this paper is the identification of the topics described, disregarded by the field of criticism.

KEY WORDS: Latin American Chronicle; Modernism; The Famous; The Plebeian.

Recibido: 12 de febrero de 2019

Aceptado: 15 de junio de 2019

Conicet-IECH-Universidad Nacional de Rosario (julietaviu@gmail.com). 
DEL DIVISMO A LA CELEBRIDAD

EN LA CRÓNICA MODERNISTA ${ }^{1}$

caballo de los siglos XIX y XX, se consolidaron una serie de para-
digmas estéticos que denominamos retóricas de la distinción
porque se sustentaron en diferencias antinómicas como lo cul-
to $v$ s lo popular, lo célebre $v$ s lo plebeyo, lo aristocrático $v s$ lo vulgar. ${ }^{2}$ En el seno del proceso de modernización, los escritores modernistas marcaron el comienzo en América Latina de las representaciones sobre figuras del espectáculo al registrar giras artísticas de destacadas personalidades europeas. Mientras que las crónicas de Rubén Darío sobre Sarah Bernhardt visibilizan la consolidación de la retórica del divismo; las crónicas de Enrique Gómez Carrillo, por incorporar figuras consideradas menores, iluminan un periodo de transición hacia la representación de las

1 Una versión más extensa de la primera parte de este apartado ha sido publicada bajo el título "La emergencia de las divas en el campo cultural latinoamericano: representaciones artísticas en la crónica modernista", Culturas 13. Debates y perspectivas de un mundo en cambio. Santa Fe: Universidad Nacional del Litoral, 2019.

2 Para definir la noción de distinción, retomamos la diferenciación que Pierre Bourdieu ([1994] 1997) establece entre capital económico, capital cultural, capital social y capital simbólico, tomando como punto de partida el tipo de capital que funciona en los campos sociales. El capital económico daría origen a un campo específico, el campo económico, y otro capital a otro campo y así sucesivamente. De allí que la noción de campo pueda ser definida a partir de esa propiedad de distribuir su propio capital específico. La definición de capital deviene entonces el conjunto de bienes acumulados que se producen, se distribuyen, se consumen, se invierten o se pierden. El capital cultural -siguiendo la lectura de Alicia Gutiérrez (Gutiérrez 2005) - es aquel ligado a la ciencia y el arte y a todo tipo de conocimientos en general (la escuela, las instituciones, los habitus, las habilidades, los valores, los bienes culturales). El capital social remite a toda "la red durable de relaciones", desde la pertenencia a un grupo a las propiedades comunes como honorabilidad y respetabilidad que procuran beneficios materiales o simbólicos. Y el capital simbólico "se trataría de una especie de capital que juega como sobreañadido de prestigio legitimidad, autoridad, reconocimiento, a los otros capitales. O sea principios de distinción y diferenciación que se ponen en juego frente a los demás agentes del campo, que se agregarían a la posición que se tiene por el manejo del capital específico que se disputa en ese campo" (Gutiérrez 2005: 40). 
celebridades que realizó, entre otros, Juan José de Soiza Reilly con su sostenida participación en Caras y Caretas a principios del Xx. Este escritor reconocido como el periodista de los famosos evidencia la configuración de una nueva etapa: una retórica de la fama cuya diferencia más notoria radica en la ampliación del repertorio de las figuras susceptibles de ingresar al campo de lo célebre. Hacia los años treinta, tuvo lugar una nueva inflexión de signo opuesto a las mencionadas, ya que la aparición de lo popular como objeto de la crónica marca un quiebre con la estética modernista al instaurar una retórica de la plebeyez que encontró en Roberto Arlt a unos de sus máximos exponentes.

El campo artístico finisecular presenta una estructura jerárquica que diferencia, por ejemplo, la alta cultura de las expresiones del vulgo. La distinción categórica entre lo sublime y lo vulgar como lógica diferenciadora de prácticas y saberes se evidenció en distintos niveles: la circulación de la literatura reprodujo dicha segmentación ya que, como explicita Ángel Rama para el caso argentino, "la lectura de los cultos era La Nación y las novedades extranjeras; la del pueblo las ilustraciones y los breves textos del primer ejemplo exitoso de revista masiva moderna, Caras y Caretas" (Rama 1986: XXIV). Por un lado, crónicas de notable extensión para un público selecto y, por otro, crónicas breves e ilustradas para el pueblo. Esta división repercutió, a su vez, sobre la oferta cultural: mientras que los sectores pudientes de la sociedad asistían a la ópera, los sectores populares consumían actos circenses y obras montadas en plazas. La incidencia de esta jerarquización artística se manifestó también en las autofiguraciones de los escritores que para definirse como tales establecieron una clara distancia con el vulgo.

A fines del siglo XIX, destacadas figuras femeninas del teatro europeo comenzaron a brindar giras artísticas por América Latina y ello conllevó que nombres como Eleonora Duse, Sarah Bernhardt y Adelina Patti aparecieran en los afiches de los mejores teatros de las ciudades capitales configurando eventos culturales apreciados por las sociedades finiseculares que fueron registrados por los escritores en tanto expresión de lo nuevo, lo cosmopolita, lo contemporáneo, en definitiva, como representaciones de escenas propias de una modernización en acto. Ello provocó la emer- 
gencia de relatos focalizados en la figura de la diva que desplazó y, en este sentido, pospuso la centralidad del tratamiento y las referencias a la obra interpretada, fenómeno que sintetizamos como el divismo.

Las crónicas que Rubén Darío publicó en Chile entre octubre y noviembre de 1886 resultan un punto de partida insoslayable para reflexionar sobre la aparición en Latinoamérica de mujeres admiradas por sociedades enteras. El diario La Época de Santiago de Chile le encargó al joven escritor que cubra las presentaciones de una de las mayores actrices trágicas del siglo XIX. Motivado por el afán de novedad, por ese deseo modernista de conocer lo que se estaba produciendo en el mundo y, especialmente, en Francia, Darío publicó singulares retratos de Sarah Bernhardt. En el Prólogo a la segunda edición de Los raros (1905), el escritor afirma: "Restan la misma pasión de arte, el mismo reconocimiento de las jerarquías intelectuales, el mismo desdén de lo vulgar y la misma religión de belleza" (Darío 2011: 37). Estos principios que afirmaba sostener desde hacía nueve años (aludiendo a la primera edición del libro) aparecen en sus tempranas crónicas chilenas. Ello permite observar la vigencia de núcleos vertebrales que este cronista defendió, como la pasión por el arte, la jerarquización intelectual, el desprecio hacia lo vulgar y el culto a la belleza. Recuperamos estos principios porque estructuran la retórica de la distinción que Darío forjó en sus crónicas sobre la diva francesa. ${ }^{3}$

En El estreno de Sarab Bernhardt, Ramadés (seudónimo utilizado por el escritor) se declara admirador "de la insigne artista" (Darío 1993: 29), confesión con la que explicita que abandona su deber de crítico para priorizar la mirada del poeta. Pospuesta la función crítica asociada históricamente a la figura del letrado, el cronista se sumerge en el espectáculo a través del registro de impresiones: el "frenesî" de la selecta concurrencia, la admiración que despierta "tan excelsa artista" así como las irradiaciones de su "portentoso ingenio", de modo que, el público adquiere el protagonismo que le correspondía a la voz del especialista. A partir de registrar

3 Las crónicas a las que nos referimos fueron compiladas a principios de los años noventa del siglo XX bajo el título Teatros. Prosas desconocidas sobre Sarah Bernhardt. 
la admiración que despierta la actriz, forja la imagen célebre. Sarah Bernhardt se destaca, entre otras cuestiones, por ese aura estelar que la individualiza: "su talento soberano, ha conseguido eclipsar la nombradía de la Ristori, la Pezzana, la Dussei, la Tessero, la Rossi..." (Darío 1993: 29). Su belleza, exclusividad y excentricidad la ubican en una posición distinguida que se observa de manera clara hacia el final de la crónica:

Y para concluir.

¿Quién es Sarah?

No sabemos decirlo.

La palabra no existe.

Sarah es lo que impele, lo que arrastra, lo que aborrece, lo que adora, lo que llora y lo que ríe.

Es mujer estatua, esfinge; es la maldad, la virtud, la firmeza indomable, la pasión que gime y se revuelve; es la soberana absoluta del arte en su más alta significación: la vida real (Darío 1993: 31).

Así, construye la imagen de una mujer sensible y seductora que define como la encarnación misma de la síntesis del arte con la vida. La diva se convierte en el motor de arranque de la crónica y, al mismo tiempo, en el punto de llegada. Si bien se vuelve una característica común a la producción dedicada a Sarah Bernhardt, destacamos la atmósfera pasional y embriagante que tiñe en especial esta crónica inaugural, donde la devoción se manifiesta a partir de la sugestión, la insinuación y la evocación, principios estéticos sostenidos por el simbolismo francés. Antes de continuar con el análisis, resulta pertinente incluir unas breves consideraciones sobre "La acción teatral. A propósito de Sarah Bernhardt" (1886) de Paul Groussac, figura paradigmática del crítico cultural, ${ }^{4}$ publicado un mes antes en $L a$

4 Paul Groussac es quien encarna, a fines del siglo xIX, el papel de crítico cultural. Paola Suárez Urtubey destaca el valor social otorgado en dicha época al especialista y lo ejemplifica con un fragmento de la nota, que reproducimos a continuación, donde La Nación anuncia el ingreso de dicho escritor como colaborador: "La Nación cuenta desde hoy con la colaboración literaria del Sr. P. Groussac, a cuyo cargo estará especialmente en nuestro diario la crítica teatral, que, en sus manos, asumirá la importancia que hace de ella en la prensa europea un alto y delicado ministerio" (Suárez 2007: 27). 
Nación. Su notable extensión, al tiempo que lo diferencia de la producción dariana, evidencia el carácter crítico del texto antologado en Viaje intelectual. Impresiones de naturaleza y arte I (1904). En la primera parte, compuesta por comentarios de las representaciones, puestas en escena y actuaciones, Groussac construye un discurso riguroso, preciso y analítico, que visibiliza la erudición que posee en el campo de la dramaturgia. La primacía de este registro técnico conlleva la censura de juicios subjetivos que sólo en contadas ocasiones deja deslizar. El contraste respecto del relato de sensaciones que Sarah despierta en Darío se vuelve aún más patente porque Groussac abunda en comentarios y reflexiones teóricas. Al señalar el talento de la actriz, el escritor franco-argentino destaca que representa "obras maestras del teatro francés" (Groussac 1904: 278). Elogio que evidencia el parámetro eurocéntrico que ha caracterizado al ilustre director de La Biblioteca. Recién hacia la mitad del escrito, se focaliza en Sarah:

tiene, pues, las dotes de una verdadera comedianta: se muestra dueña absoluta de sí propia y de sus efectos escénicos. Pero no mucho más que la coqueta mundana que engaña en la misma noche a diez adoradores, o nuestro amigo Don Juan, al fingir admirablemente su momentánea pasión, pues la bipocresía, es decir la acción cómica, es una aptitud natural que casi todos poseemos. Procuremos, pues, analizar en pocas palabras ese talento de gran hipócrita (Groussac 1904: 285).

Esta autofiguración como especialista dotado de facultades intelectuales le permitió asumir el papel de juez cultural con esa "conciencia de aristos" (Rama 1986: 39) propia de los escritores finiseculares. Además de la construcción de esa voz narrativa autorizada por su capacidad para analizar el hecho artístico, interesa el singular retrato que forja a partir de una descripción fisiológica minuciosa que combina reminiscencias lombrosianas con expresiones poéticas: ${ }^{5}$

5 Con la expresión "reminiscencias lombrosianas" referimos al discurso positivista criminológico, desarrollado entre otros por el médico César Lombroso, quien a fines del siglo XIX había establecido una clasificación de los criminales a partir de rasgos físicos que permitían identificarlos. 
La cabeza no es regularmente hermosa, si bien toda ella modelada en fracciones expresivas, que forman un conjunto de extraña seducción. La fisonomía está hecha de relieves y méplats: ninguna redondez. La curva netamente hebraica del perfil se interrumpe de golpe sobre el duro relieve del labio corto $[\ldots]$. Las alas de la nariz se dilatan fácilmente en los momentos de pasión; durante los raptos de ira, el músculo piramidal se hincha agresivo, entre las cejas fruncidas. El párpado espeso cubre los admirables ojos de agua marina o turquesa, pues su color parece mudable como el del mar (Groussac 1904: 286).

El retrato pone en juego una tensión entre la descripción de la fisonomía, marcada por la precisión nominativa que le otorga cientificidad al discurso, y las expresiones metafóricas que distienden la densa enumeración. Focalizado en la actriz, Groussac destaca su voz aunque señala que presenta debilidades en la destreza gestual. La crónica concluye —no podía ser de otra manera- con un juicio crítico: "Sarah Bernhardt no logró nunca realizar a la perfección las primeras figuras; pero nadie supo como ella prestar a las segundas color intenso y relieve eficaz" (Groussac 1904: 290). Esta representación ilumina la distancia que media entre el estudio riguroso y la primacía de la impresión subjetiva en Rubén Darío cuya mayor diferencia radica en la representación de la protagonista: el escritor nicaragüense forja la imagen de la diva, mientras que Paul Groussac trabaja con la actriz. Edgar Morin advierte una diferencia importante al respecto: "La estrella es el actor o la actriz que absorbe una parte de la sustancia heroica —es decir, divinizada y mítica - de los héroes de cine, y que, recíprocamente, enriquece esta sustancia mediante un aporte que le es propio" (Morin 1966: 45). La apreciación apunta al proceso de divinización capaz de convertir a una actriz en una diva y, por ende, se vuelve pertinente para abordar a la Sarah dariana.

Una característica de Sarah Bernhardt que Rubén Darío recupera es su singular belleza que nombra con adjetivos de refinamiento y excelencia: es la "soberana absoluta del arte" (Darío 1993: 37), "mujer sensible y seductora" (1993: 31) de un "temperamento excepcional" (1993: 35). Además de referir a las cualidades físicas, la belleza supone la encarnación del ideal artístico y, en este sentido, vehiculiza una crítica a la sociedad mate- 
rialista finisecular. ${ }^{6}$ Darío ratifica que se trata de un ser extraordinario aunque podríamos afirmar que lo que más admira es que "todos los vicios y las virtudes, todas las debilidades del alma, todos los arranques generosos de un corazón hidalgo, tienen en el semblante, la voz y la actitud de Sarah sus medios más apropiados de expresión" (Darío 1993: 36). Advierte en definitiva a una mujer que trasciende el sujeto moderno, un ser pasional gobernado por sus sentimientos. En ese gesto ciframos el rechazo que el modernismo latinoamericano manifestó hacia la modernidad entendida como realización del proyecto normativo de la Ilustración especialmente en tres factores: el desarrollo de la ciencia, la moralidad y el arte de acuerdo a sus lógicas internas y de manera autónoma. ${ }^{7}$

El divismo resulta contestatario a la concepción burguesa de la vida producto del incipiente régimen capitalista y enarbola el lugar central del arte como desafío a las prácticas utilitarias; la expresión sublime como bandera contra el materialismo reinante; lo excepcional de las representaciones artísticas frente a la vulgaridad de la realidad cotidiana; el ser pasional frente al homo economicus. Paradójicamente el divismo se sustenta en uno de los pilares centrales de la cosmovisión burguesa como es el individualismo, ya que exalta al sujeto individual en detrimento de las nominaciones colectivas. Rafael Gutiérrez Girardot sostiene que ésta se rige por "el egoísmo como principio general, las dependencias recíprocas, el interés propio y el principio de utilidad" (Gutiérrez 2004: 45). Así como la burguesía concibe al ciudadano como sujeto privado motivado por la realización de intereses particulares, el estrellato demanda a las divas la

6 Enrique Foffani desarrolla el sentido que la belleza tuvo para los modernistas en tanto categoría secular: "La belleza en tanto que territorio estético de la fantasía poética en un sentido amplio y no sólo en el estricto del género, opera en el modernismo hispanoamericano como una presencia disidente que debe enfrentar los valores impuestos y, por ende, defendidos por una modernidad rastacuera y servil [...]. Contra el baño de utilitarismo del que ya no pueden sustraerse todas las cosas, la belleza es el ámbito por antonomasia de la resistencia del artista en su intento por sobrevivir al tiempo presente percibido como una crisis histórica radical, preñada de angustia y de un sentimiento amargo de la existencia. La belleza repudia la moral filistea del capitalismo y contrapone la moral sublime del arte" (Foffani 2007:14).

Para un desarrollo en profundidad, véase Habermas 1983. 
construcción de una firma, de un nombre propio capaz de designar a un sujeto inconfundible, inimitable y singular.

Las crónicas que Enrique Gómez Carrillo publicó durante la primera década del siglo XX, inscritas en la estética modernista, amplían el repertorio de artistas circunscrito a la diva, al sumar a cantantes populares, bailadoras y geishas. ${ }^{8}$ Sus crónicas se configuran como una transición entre el divismo modernista y la celebridad como será configurada, por ejemplo, en las crónicas de Juan José de Soiza Reilly, ya que alterna entre crónicas dedicadas a estrellas internacionales (Gabriele Réjane, Marta Brandés y Eleonora Duse) y otras ligadas a lo que en aquel entonces se consideraba el "arte menor". Resulta llamativo que artistas pertenecientes a este último campo como Raquel Meller y Loie Fuller fueron capaces de despertar el reconocimiento del círculo de escritores e intelectuales. María Luisa Bastos llama la atención sobre la singular recepción que el guatemalteco tuvo en un amplio público y de manera sostenida en el tiempo, y señala la doble condición del escritor: "cónsul de productos intelectuales y de snob" (Bastos 1989: 57).

Este cronista volvió accesible para un público no especializado asuntos complejos: "la mayoría de sus crónicas parecen reclamar 'participantes' poco habituados a la experiencia artística, que se satisfarán si se les proporciona un producto en el que se ha homologado diestramente, profesionalmente, lo estético y la moda" (1989: 57). Las crónicas de Gómez Carrillo empezaron a desafiar la división sobre la que se asentó el Modernismo latinoamericano entre arte elevado y cultura de masas. Una operación que lo diferencia se observa en el título elegido para la sección que agrupa dichas crónicas: "Mis ídolas". En el marco de la secularización que supone la desacralización del ámbito religioso y la sacralización de sujetos y objetos mundanos, la sustitución de divas por ídolas cobra un valor particular al poner en primer plano la tensión sagrado/profano. En tér-

- El libro de las mujeres, antología que recupera las crónicas analizadas, cuenta con una primera edición de 1909 en París por la editorial Garnier Hermanos. La edición definitiva (que citamos en este artículo) se editó en 1919 en Madrid por la editorial Mundo Latino. 
minos etimológicos, ídolo remite a dioses bastardos porque recupera el sentido bíblico que, como advierte Joan Corominas en Breve diccionario etimológico de la lengua castellana (1961), remitía a la prohibición de tener imágenes de ídolos o falsos dioses; sentido que el propio Gómez Carrillo recupera en su Diccionario ideológico para facilitar el trabajo literario y enriquecer el estilo cuando sostiene que se trata de una "falsa divinidad, fetiche, idólatra, pagano, infiel, iconolatra, idolatría, gentilidad, paganismo, fetichismo, iconolatría" (Gómez 1925: 382). La elección de dicho término para nombrar la devoción personal hacia una serie de mujeres contemporáneas evidencia, como plantea Enrique Foffani, el proceso de secularización literaria: "la incidencia del proceso de secularización en el discurso literario a través de la lengua y del imaginario social que atraviesa la dimensión simbólica e institucional de la experiencia del sujeto moderno" (Foffani 2010: 15-16). De modo análogo al famoso poemario dariano Prosas profanas que muestra la secularización por medio de la enunciación dicotómica, Gómez Carrillo elige un término que contiene dicha tensión.

La cantante española Raquel Meller, representante de la canción popular que encabeza la serie de ídolas, visibiliza el reordenamiento propuesto por el cronista cifrado en el gesto de iniciar con una figura dedicada al "arte menor". El gesto de posponer a las divas resulta cuanto menos provocativo para una estética exquisita como la modernista, ya que la crónica pone en escena la marginalidad de la artista para explicitar que la elección ha sido intencional: "Los que conocen la armonía impecable de su dicción y admiran la ciencia exacta de sus gestos, le aconsejan que abandone el 'arte inferior' que cultiva para consagrarse a la comedia. Yo, por el contrario, creo que no debe cambiar de género" (Gómez 1919: 81). La representación de la discusión pone de manifiesto que la cantante contaba, en aquel momento, con el reconocimiento de artistas e intelectuales que consideraban desafortunado que desaproveche su talento. ${ }^{9}$ Gómez

9 Rafael Cansinos Assens publica en la revista Cosmópolis una nota en la que destaca el valor artístico de la cantante. Allí, el crítico español vislumbra el mito cinematográfico que se forjará tiempo después sobre aquella mujer. En el artículo, 
Carrillo opera por medio de un doble movimiento: adelanta la crítica que se le hacía a la intérprete (allí puede leerse el miedo a la contaminación que sentía el arte culto respecto a las manifestaciones artísticas populares) y expone su opinión a favor de la elección realizada. El cronista marca una diferencia: nuestra hipótesis de lectura es que se permite detectar rasgos modernistas en expresiones, que en términos de dicha estética, deberían calificarse de vulgares. La identificación de dichos rasgos supone un acto de valorización de la artista en tanto arte elevado y no en su condición popular que queda ilustrado no sólo en las palabras inaugurales citadas sino también en el apartado siguiente:

Yo la veo todas las noches. Y si no me equivoco, todas las noches la oigo cantar las mismas coplas a los acordes de las mismas musiquillas. Pero no sólo no encuentro nunca que se repita, sino que cada vez me parece asistir a una nueva creación, oír un nuevo acento, extasiarme ante una nueva belleza (Gómez 1919: 82).

Si bien reconoce la pertenencia de Raquel Meller al cuplé, género popular español, la destaca por el tipo de interpretación que realiza de aquel arte monótono y repetitivo. Allí, observamos otra diferencia con Rubén Darío: mientras que éste apela a la hipérbole para representar a su musa Sarah Bernhardt, Gómez Carrillo recurre a la paradoja (una artista dedicada al arte popular que no se repite). Este retrato tensiona de manera constante lo viejo de la canción y lo nuevo de la interpretación, lo mismo

destaca la originalidad y la innovación artística: "Lo que sobre todo caracteriza 'el arte incomparable' de Raquel Meller, lo que constituye su aportación original al ara de los escenarios menores, es el haber dramatizado la canción popular, dotándola de complejidad y plenitud literarias. [...] Raquel hizo de la canción un poema dramático [...] Raquel lo dotó de un alma profunda y grave, lo cobijó con un pliegue de la antigua vestidura trágica" (Cansinos 1919: 647). Dos cuestiones nos interesan de esta cita: por un lado, observamos la persistencia del discurso de la gran división ya que, al igual que en la crónica de Gómez Carrillo, aquí vuelve a aparecer la tensión entre su calidad equiparable al arte mayor pero en el marco del arte menor y, por otro lado, visibiliza que si bien en aquel momento no constituía el mito que forjará tiempo después ligado a su trabajo cinematográfico, se trataba de un personaje de renombre para la época y que resultaba atractiva para la intelectualidad. 
y lo distinto, en definitiva, podríamos pensar que constituye - si se nos permite la expresión - un producto popular modernista. Por supuesto que lo popular refiere a la recepción de un público amplio y no a la representación de lo vulgar. Con la expresión "producto popular modernista" pretendemos visibilizar que, de acuerdo al retrato del cronista, esta cantante resulta la encarnación de la estética modernista. En la "Dedicatoria" a Emilio Mitre, de la antología Entre encajes, Gómez Carrillo explicita su deseo de que "no se vulgaricen mucho" estos retratos dirigidos a hombres serios de "frágiles figuras que bailan, que ríen, que se pasman, que son inconscientes [...], que son muy caprichosas y muy bonitas y muy coquetas" (Gómez 1909: vi). Complicidad entre hombres de letras que respalda nuestra lectura: la legitimación de ciertas figuras desde y para el arte culto.

El espectáculo de Raquel Meller resulta representativo de la estética modernista en que además de ser original ella aparece a los ojos del cronista como un ser auténtico: "siendo altiva y humilde, perversa y sencilla, suave y traviesa, ferviente y ligera; siendo una gran dama y una modistilla, una parisina y una andaluza; siendo buena y mala, cruel y piadosa; siendo múltiple e inexplicable, en suma, es siempre ella misma y no es más que ella" (Gómez 1919: 85). La elección de esta artista demuestra una posición abierta hacia las expresiones que atraen a un público amplio; sin embargo, esa mirada benevolente hacia el "arte menor" en los términos empleados por el propio cronista responde a que reconoce en la intérprete las cualidades propias del arte mayor: Gómez Carrillo valora a Raquel Meller no por lo que presenta de popular sino por sus inigualables cualidades artísticas.

Otra crónica que reviste interés por la tensión que se produce entre la estética modernista y las expresiones vulgares es la dedicada a la bailarina estadounidense Loie Fuller. Motivada por la aparición del libro de memorias de la artista publicado en 1908, esta crónica presenta una serie de rasgos comunes a la de Raquel Meller que permiten observar el modo en que Enrique Gómez Carrillo opera ante lo que dimos en llamar productos populares modernistas: la conversión de figuras ambiguas en términos de prestigio artístico en representaciones modernistas con el objetivo de legitimar la apropiación por parte de lectores cultos. La pri- 
mera similitud se presenta en el tratamiento así como en la perspectiva de abordaje del objeto de escritura: "por lo mismo que es un hada, su arte escapa a todo análisis. Uno ve, se asombra, y luego no conserva sino una visión trémula de milagros. ¿Poner en palabras esa visión? Muchos han querido hacerlo. Las grandes dificultades tientan a los grandes artistas" (Gómez 1919: 103). El cronista marca los límites que el discurso técnico presenta para dar cuenta de este tipo de expresiones artísticas y, por lo tanto, apuesta por la literatura: "Lo mejor, tal vez, para dar una idea aproximada de las invenciones de esta mágica prodigiosa, sería renunciar a todo esfuerzo verbal y contentarse con decir, como dicen los cuentos orientales: 'Era un hada..." (1919: 103). Otro punto de contacto estriba en la representación de la protagonista al explicitar que no pertenece al arte culto y, en seguida, sacralizarla al reconocerle cualidades artísticas. La bailarina estadounidense deviene un hada armonía que recuerda "Era un aire suave" de Rubén Darío:

Es hada; es hada de ritmos luminosos, hada tan poderosa, que respira en el éter inflamado cual si fuera una princesa metamorfoseada en salamandra; es hada que palpita entre las llamas acariciadoras, y que sonríe; es hada sutil que ha hecho melodías de fuego, melodías de luz, melodías de iris. Es el hada Armonía de que hablan los poetas (1919: 103).

Loie Fuller resulta una verdadera artista que se destaca por la capacidad de manejar el ritmo (ese ritmo que Gómez Carrillo trasmite en la aliteración de la palabra hada), la armonía, los matices, los tonos, las luces y los colores. La danza serpentina que creó hacia 1890 significó una verdadera revolución para el arte de la época por la gran cantidad de técnicos así como por la tecnología empleada en el espectáculo. La presentación de la misma tuvo lugar en el cabaret parisino Folies-Bergère, donde se ofrecían números de ballets, operetas, pantomimas y números circenses. En referencia a ello, María Luisa Bastos sostiene que "Loie Fuller no bailaba en cenáculos frecuentados sólo por artistas, su fama fue una fama del gran público" (Bastos 1989: 66). La fascinación que la bailarina despertó no sólo para el público popular sino también para los artistas puede dimen- 
sionarse por el hecho de haber sido filmada por los hermanos Lumière en 1897. Gómez Carrillo encontró en ella a una "divina sacerdotisa" (Gómez 1919: 101) que ha comprendido que su arte "es superior a la danza y superior al teatro mismo" (1919: 100). La idealización que permite la sacralización radica en que "ha creado la 'danza absoluta', la danza integral, es decir, la danza que no se aprende en los conservatorios, la danza que es la expresión verdadera de la vida pasional" (1919: 104). Vuelven a hacerse presentes los principios modernistas como la actitud antiacadémica y la valorización de lo instintivo por sobre lo instituido. La producción cronística de este escritor cifra un momento de quiebre del miedo modernista a la contaminación de expresiones artísticas menores aunque no abandona las grandes figuras femeninas del momento. En este sentido, el divismo adquiere otro modo de expresión: las protagonistas supeditan el espectáculo a su figura aunque, a diferencia de las crónicas darianas, el escritor juega un papel activo en la sacralización de estas estrellas bivalentes entre lo culto y lo popular.

DE LA CELEBRIDAD CONSAGRADA

A LA EMERGENCIA DE LO PLEBEYO

Mi corazón me impide ser modesto. Tampoco quise serlo. $Y$, aunque quisiera serlo, no podría...

Hace muchos años que vivo en el ambiente de los hombres célebres.

Juan José de Soiza Reilly, "Palabras interiores".

La retórica del divismo fue reemplazada a principios del siglo XX por una retórica de la fama abocada a hombres destacados de la alta sociedad, del ámbito religioso y artístico. Juan José de Soiza Reilly se consagró por entonces como el entrevistador de las personalidades famosas al colaborar para Caras y Caretas. Este material publicado entre 1907 y 1908, recopilado en Cien hombres célebres (Soiza 1909), provocó un cambio con el paradigma anterior al instaurar representaciones de personajes célebres en 
términos más generales. Las celebridades aparecieron como un fenómeno de masas (Ludmer 2011) producto de la emergente cultura del consumo así como de la profesionalización del periodismo. En cambio, el divismo remitía a representaciones de un selecto grupo artístico consumido por un restringido público. Ahora bien, resulta importante advertir que si la celebridad refiere, como entiende Josefina Ludmer, a la conformación del nombre propio en noticia, esto es, en mercancía de la prensa, ella emerge con el divismo en las crónicas modernistas que se consolidaría con las crónicas sobre personajes célebres. En este apartado, iluminamos, por un lado, la continuidad del divismo en la celebridad al considerar que ambas retóricas se fundan en el discurso dicotómico que divide lo alto de lo bajo, lo culto de lo plebeyo y, por otro, puntualizamos aquellas diferencias que permiten advertir el nuevo paradigma.

La escritura de Soiza Reilly se asienta sobre el discurso de la fama y, en este sentido, habilita dos tipos de protagonistas: la mayoría de ellos son sujetos distinguidos por la clase social a la que pertenecen (reyes, condesas y príncipes) o miembros del campo artístico (poetas, pintores, escultores y músicos); y otro tipo de protagonista, que aparece en un reducido número de crónicas, son sujetos sin estatus social ni cultural que se diferencian de la masa por haber vivido algún suceso extraordinario ("La historia de un lustrabotas", "El filósofo de los perros"). Estos últimos que parecieran contradecir el concepto de bombre célebre no hacen más que confirmar la imbricación entre celebridad y fama (sea esta última adquirida por la difusión que se tiene de alguien o de algo).

La autofiguración de Soiza Reilly resulta similar a la de los modernistas al afirmarse en los nobles valores del arte. Entre las más célebres, recordamos la de Rubén Darío: "Yo no soy un poeta para las muchedumbres. Pero sé que indefectiblemente tengo que ir a ellas" (Darío 1977: 243). Ecos de ella escuchamos en "yo no formo parte de la muchedumbre. Alimento mis sueños con el producto de mi propia huerta. Tengo mis creencias. Quiero más lo mío que lo tuyo. No copio las modas del Petronio de enfrente. Camino siempre solo. Tengo mi sendero" (Soiza 1909: 9). Tanto Soiza Reilly como Darío se conciben como hombres de letras en oposición a 
la multitud y plantean en términos discursivos su pertenencia al grupo de artistas que supone la exclusión del vulgo. No olvidamos que Soiza Reilly presenta la particularidad de encontrarse en un lugar desplazado con respecto a los escritores por estar fuera de "la comunidad" (1909: 9). Él alude a su condición de periodista sin una obra por fuera del trabajo en la prensa cuando la mayoría de los modernistas eran poetas además de cronistas. Sin detenernos en ello, destacamos de la cita el sistema de valores que establece una diferencia tajante entre el arte refinado y el arte vulgar, el escritor y el reportero, el hombre célebre y el hombre común. Además el principio de originalidad así como el valor otorgado a la creación y a lo subjetivo, donde resuenan las "Palabras liminares" de Prosas profanas, proclaman una estética acrática. La autofiguración modernista de Soiza Reilly paradójicamente apareció en el primer semanario ilustrado de tirada masiva de Buenos Aires (Szir 2013).

Este abanderado de los distinguidos se autoriza por su condición de testigo de los ilustres. En Crónicas de amor, de belleza y de sangre (Soiza 1911), declara ser el periodista de las celebridades que ha visto de cerca y que ha vivido en el ambiente de los hombres célebres, condición que le permitió legitimar su escritura a partir de la experiencia. Soiza Reilly pretende dar testimonio de primera mano apelando a la tradicional figura del narrador-testigo característico de las crónicas de Indias donde el valor de veracidad resulta fundamental. Su pertenencia al grupo de los selectos le permite jactarse de una arrogancia que dice heredar y que le impide ser modesto como declara en el fragmento citado a modo de epígrafe.

Un rasgo que prevalece en su escritura es la audacia con que se aproxima a los personajes. Recordemos que sus crónicas fueron producto de encuentros y visitas que le permitieron conocer la "intimidad de la fama". Con esta última expresión, Ludmer refiere al objetivo de llegar a conocer el alma de los célebres antes que sus palabras, conceptualización que parte de una hipótesis planteada por el propio escritor en la crónica al abate Lorenzo Perosi: "No hay medio más eficaz para desnudar a un hombre célebre, que ponerlo frente al objetivo [de la cámara]. Nadie quiere pasar a la inmortalidad con las guías del bigote torcido o el gesto avinagrado" 
(Soiza 1909: 20). Después reflexiona sobre la importancia de la entrevista: "Es necesario moverle su amor propio. Hacerle hablar. Calarle. Estudiar las 'poses' premeditadas que improvisa. Después, es necesario tocar en su espíritu ciertos resortes de sensibilidad para que hable. Pero es necesario hacerse en su presencia el pequeñito" (Soiza 1909: 19). Estas metarreflexiones manifiestan el agudo conocimiento del oficio de periodista e iluminan la arquitectura de las crónicas a celebridades, que tomando la forma de la entrevista, dan cuenta de ser producto de un entrevistador alejado del simple curioso.

Soiza Reilly pone en escena en numerosas ocasiones las dificultades que debe sortear para conseguir encontrarse cara a cara con los protagonistas. La figuración de periodista sacrificado se vuelve un lugar común provocando la homogeneización de una voz narrativa inconfundible singularizada por la audacia. En la crónica "Benito Pérez Galdós":

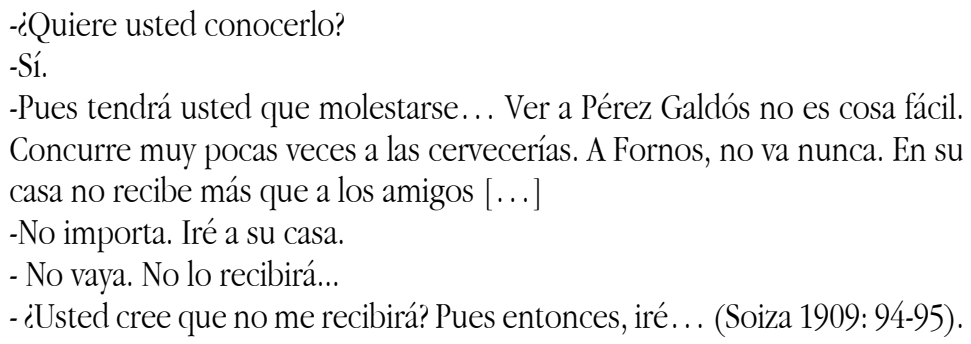

La reiteración de esta autorrepresentación permite suponer que sus lectores deben haberlo concebido como un periodista perseverante, un protopaparazzi curioso y entrometido que no esperaba la noticia sino que salía a buscarla. En muchas ocasiones, Soiza Reilly empieza por recrear la escena de la entrevista y así genera una fuerte presencia de su voz que invita a oír lo que dijo tal o cual personaje. En consonancia con ello, sus crónicas fueron concebidas como una aventura: en "Una entrevista con S. M. el rey de España”, narra los protocolos que debió cumplir para acceder a un encuentro cara a cara con el rey después de anoticiar al lector de que éstos no reciben periodistas: 
En las puertas de entrada, la infantería, la caballería, los alabarderos, la policía... Después los porteros de pantalón corto, guante blanco y el pecho lleno de medallas. Al pasar los alabarderos os miran y os detienen. Mostráis el permiso [...] Luego os hacen entrar a un salón granate. Después os llevan por un frío corredor. En seguida os van deteniendo más porteros, más lacayos, más mayordomos. [...] Luego pasáis a otro salón [...] Un alabardero, de perita, os detiene. Mostráis la contraseña [...] Otro alabardero... (Soiza 1909: 58)

Este largo y tedioso ingreso concluye cuando se concreta el encuentro: "creéis que os espera un ser supraterrestre. [...] ¿Y qué veis? iOh, sorpresa! [.. . ] Vi un jovencito. Un Felipe IV sin vejez. Un muchacho alto, delgado sin ser flaco. Una cara pálida [...] (Aquel hombre que se ponía de pie ¿era un rey?)" (Soiza 1909: 59). Al oponer los protocolos de la realeza con la sencillez del personaje Alfonso XIII, Soiza Reilly convierte la entrevista en una crónica, donde logra que el fenómeno de la celebridad también lo incluya y lo convierta en un escritor best-seller aunque no haya pasado a la posteridad porque sabemos que fue un cronista olvidado (Ludmer 2011, Terranova 2006). La crónica "Catulle Mendés, Remy de Gourmont y Augusto Rodin" enfatiza un discurso jerarquizante que diferencia el arte de las expresiones populares. Hallar a estos tres representantes de "la belleza" en el teatro lo motiva a escribir un "retrato literario para presentarlos al público de América".

Al pasar [Rodin], la plebe le arroja un grito, lleno de verde espuma:

- iLoco! iLoco! iLoco!

Pero Rodin pasa envuelto en el silencio de su orgullo de esfinge. El pisotón de sus botines rudos hace crujir los huesos de la salvaje muchedumbre, que cuando lo admira es, precisamente, cuando no lo comprende... (Soiza 1909: 76).

La insalvable distancia que media entre el artista y la plebe impregna todo el relato. La polarización se juega en una serie de tensiones: el alboroto y el sigilo, lo impulsivo y la prudencia, la incoherencia y la cordura, la ignorancia y la sabiduría. Soiza Reilly ilumina el vínculo entre arte y sabiduría como posibilidad de superar lo común, lo ordinario, el clisé. En 
"La vida artística de Gabriel D’Annunzio", observamos un razonamiento similar: "Figuráos sentir en vuestras venas el encanto de un crimen. No de un crimen vulgar. No de un crimen sin arte. . i in crimen sabio!" (Soiza 1909: 86). Si el modernismo — como señala Rafael Gutiérrez Girardotconvirtió al artista en objeto novelable (2004: 54) (De sobremesa, de José Asunción Silva, resulta el ejemplo paradigmático), la novedad de Soiza Reilly radicó en incluirlos en el grupo de los hombres célebres. Allí, marca una diferencia con libros contemporáneos como Los raros (1896) de Rubén Darío o Almas y cerebros (1898) de Enrique Gómez Carrillo, donde los escritores aparecen entre escritores o junto a otros representantes del campo artístico.

Juan José de Soiza Reilly instauró el concepto de hombre célebre, que incluye a hombres y mujeres con vidas singulares al consolidar una retórica de la fama basada en lo superlativo, lo exclusivo y lo auténtico. Este último rasgo se visibiliza de manera clara en "Una bohemia de la aristocracia", que dedica a Gloria Laguna: "Hace lo que hace, porque sí. No finge, No miente. No trata de seducir. Seduce... Si a los labios le asoma una palabra, la deja caer. Nada más" (Soiza 1909: 15). La franqueza, uno de los principios que definen a este tipo de personalidades, aparece así como un rasgo sobresaliente de esa mujer polémica para su época por haber hecho público su deseo sexual por las mujeres. La categoría no resulta sencilla de asir y quizás el principal obstáculo radique en su amplitud. A los fines de esclarecerla aunque sin la pretensión de construir una taxonomía exhaustiva, puntualizamos algunos rasgos fundamentales de estos "grandes hombres": la superioridad de clase, la autoridad moral, el refinamiento artístico y la sabiduría. Entre los hombres célebres encontramos aristócratas, artistas, escritores, eclesiásticos y hombres de ciencia, en definitiva, notables personalidades de la vida cultural, política y social del periodo finisecular. A diferencia de la concepción modernista, lo célebre no refiere a una condición personal (subjetiva) como podrían ser las cualidades artísticas, sino que responde, en buena medida, al fenómeno de recepción, a la difusión que determinada figura o suceso tenga en la sociedad. La fama, entendida como aquello de lo que se tiene noticia, pasa a ocupar el 
lugar que tuvo lo culto en el divismo modernista. El cambio de paradigma puede pensarse como el pasaje del hombre cultivado (el hombre de arte) al hombre famoso.

El desplazamiento a un segundo plano de la representación de celebridades tuvo lugar con la aparición de crónicas que se abocaron a poner en escena un mundo eminentemente popular, protagonizadas por clases bajas y escritas con un vocabulario que para la época resultaba ordinario. A mediados de los años treinta del siglo Xx, se configuró un tercer paradigma que denominamos retórica de la plebeyez, caracterizado por la reivindicación de expresiones populares. Esta consolidación de lo plebeyo como objeto literario se inscribió en el proceso artístico encabezado por los movimientos vanguardistas latinoamericanos de mediados de los años veinte que bregaron por la ampliación de los temas literarios. En el campo de la crónica Roberto Arlt es uno de los primeros que se dedicó de manera exclusiva a representar a personajes anónimos. Las crónicas de la antología Las muchachas de Buenos Aires (1969), que reúne aguafuertes publicadas a finales de los años veinte, ilustran aquella renovación temática y formal que visibilizó el quiebre con la retórica de la distinción de las crónicas sobre divas y bombres célebres. Rescatamos la autorrepresentación que brinda de sí mismo en "En el Rodolfo Aebi": "Hay dos formas de viajar. Una, en nave de recreo, realizando la molesta vida social que imponen los cruceros de placer. Otra, la que he escogido yo, deliberadamente, conviviendo con gente que trabaja a bordo, imponiéndome sus costumbres, convirtiéndome en casi uno de ellos" (Arlt 2016: 9). Estos modos de viajar simbolizan modos de habitar el mundo: Roberto Arlt ha elegido conocer, escribir y, por lo tanto, divulgar la forma de vida de las clases populares y hasta tuvo el objetivo de llegar a amalgamarse con ellos a pesar de que sabía que no era posible.

Sus aguafuertes se constituyeron como tales en el seno de la emergente prensa popular argentina. Publicadas en el diario El Mundo entre 1928 y 1942, comenzaron siendo una "nota costumbrista, una columna diaria, anónima” (Saítta 1994: 9) y, en pocos meses, la columna encontró el nombre (Aguafuertes porteñas) y apareció firmada. La reiteración del 
nombre propio del escritor en la columna convirtió al cronista en un periodista estrella. Sylvia Saítta destaca que "traer en un periódico porteño de vasta circulación una sección firmada, era un lujo que pocos alcanzaban" (Saítta 1994: 9). Roberto Arlt ocupó un lugar central en el proceso de consolidación de la prensa popular ya que su escritura se moldeó al interior de El Mundo o, para ser más precisos, según las demandas de los "nuevos lectores" que buscaban entretenerse (Saítta 1994: 8). La conciencia de ello se refleja en la estrategia de representar un vínculo fluido y próximo con los lectores a través de dos roles que alternadamente asumía el cronista: el consejero que les indicaba a las mujeres lo que les convenía hacer y, por otros, el defensor de esta minoría que denunciaba las injusticias padecidas por ellas. Probablemente, sea esto lo que haya facilitado la identificación y la empatía. Las protagonistas representan mujeres sacrificadas y oprimidas familiar y laboralmente como se ejemplifica en "La muchacha del atado":

Todos los días, a las cinco de la tarde, tropiezo con muchachas que vienen de buscar costura.

Flacas, angustiosas, sufridas. El polvo de arroz no alcanza a cubrir las gargantas donde se marcan los tendones; y todas caminan con el cuerpo inclinado a un costado: la costumbre de llevar el atado siempre del brazo opuesto.

[...] No se trata de hacer sentimentalismo barato. No. Pero más de una vez me he quedado pensando en estas vidas, casi absolutamente dedicadas al trabajo (Arlt 1969: 14).

Mujeres dedicadas al trabajo constituyen escenas que este cronista ve a diario. En este caso, refiere al sacrificio de mujeres que de niñas debían cuidar a sus hermanitos y que cuando crecían se pasaban la vida sobre la máquina de coser. Estas mujeres "de nuestro ambiente pobre" (1969: 15) nunca dejaban de trabajar porque, cuando habían terminado los encargos, empezaban las demandas de su propia casa. El problema de dinero aparece también en "La empleada que hace guardia el domingo" (1969), que representa a una mujer que no cuenta ni con un día de descanso a la semana. De esta manera, Roberto Arlt construyó una galería de retratos de 
la clase asalariada de las primeras décadas del siglo exponiendo las injusticias que debieron soportar fueran éstas oficinistas, santeras, lavanderas, planchadoras o costureras. Fueron representadas en términos genéricos sin nombre propio y sin la posibilidad de ser identificadas más que en su conjunto (las carboneras, las amas de casa, etc.) y, por supuesto, definidas a partir del tipo de trabajo que realizaban, aspecto que evidencia la configuración de un paradigma opuesto al de la celebridad embarcado en la tarea de retratar individualidades.

Los títulos resultan iluminadores del modus operandi de esta escritura plebeya interesada en visibilizar aquello que permite armar un conjunto y no en destacar singularidades. A los títulos referidos, agregamos "La muchacha en el balcón solitario" (1969) y "La mujer que juega a la quiniela" (1969). Roberto Arlt apeló a los sustantivos comunes para brindar la idea de indeterminación o generalidad que imposibilitara identificar una individualidad. Allí, se visualiza un quiebre con la escritura sobre divas ya que, aun cuando utilizó sustantivos propios ("Angelita, María o Juana, la tarde del sábado trabajan para los hermanos"), (15), los nombres perdían su poder individualizador al inscribirse en una enumeración que finalizaba con el nexo coordinante disyuntivo que indica una opción entre otras y que aporta la idea de sustitución.

La defensa de lo plebeyo manifiesta no sólo la conciencia del autor de la importancia de visibilizar dicho objeto sino también el sostenido interés que tuvo por éste. A nivel semántico, supuso el protagonismo de mujeres comunes y corrientes que se caracterizaron por una doble marginalidad (por su condición femenina así como por su condición económica). Esta elección temática tuvo lugar en medio de debates sobre cuáles eran y cuáles debían ser los temas literarios. En El conventillo de nuestra literatura (1969), testimonia el enfrentamiento: "El señor Lugones encuentra bolcheviques a los escritores que, como Mariani, Barletta, Castelnuovo, Tuñón y yo, quizá, se han ocupado de la mugre que hace triste la vida de esta ciudad" (Arlt 1994: 54). El posicionamiento asumido por Roberto Arlt respecto a la incorporación de formas lingüísticas propias del habla popular implicó el rechazo, la descalificación y el repudio de autores como 
Leopoldo Lugones, figura modelo del escritor argentino -sostenemos con Adolfo Prieto (1968) - , que ponderaron las formas refinadas de la lengua. ${ }^{10}$ Los cuestionamientos de los escritores consagrados no impidió el desarrollo de esta vertiente popular que estamos analizando.

Lo plebeyo refiere también a una clase social signada por la pobreza y la explotación; sin embargo, no se limita a una cuestión temática. El posicionamiento del escritor frente al lenguaje visibiliza la construcción de una estética plebeya producto de la incorporación del lunfardo así como de la oralidad barrial. Elección que buscó diferenciarse de la selecta lengua poética así como del aristocrático vocabulario heredado del modernismo. Con una nueva concepción del escritor y de la lengua, Roberto Arlt elige para sus aguafuertes el lenguaje popular, el "léxico del pueblo":

Yo tengo esta debilidad: la de creer que el idioma de nuestra calle, el idioma en que conversamos usted y yo en el café, en la oficina, en nuestro trato íntimo, es el verdadero ¿Que yo hablando de cosas elevadas no debería emplear estos términos? ¿Y por qué no, compañero? Si yo no soy ningún académico. Yo soy un hombre de la calle, de barrio, como usted (1994: 31).

La defensa del lenguaje corriente surge, según cuenta el escritor, de la diversidad de opiniones que recibe en las cartas de lectores. Ante la queja de algunos por las expresiones empleadas, explicita su posicionamiento: escribe con el "lenguaje de la calle" porque se trata del idioma de sus destinatarios, una forma cotidiana, natural y comprensible para todos. El comentario del escritor resulta contestatario de por sí porque rompe con las formas socialmente aceptables para la escritura. Roberto Retamoso advierte que:

10 Adolfo Prieto sostiene que Lugones representó la imagen por antonomasia del escritor argentino: "joven de veintidós años, con un verbo incendiario y una audacia que impresionaron a observadores nada vulgares como Darío y Groussac. Desde la etapa de iniciación, Lugones demostró un particular interés por dominar las posibilidades expresivas del idioma, junto con una capacidad de mimetismo que le permitía adoptar como propios estilos y maneras literarias diversas. Aquella preocupación y esa facilidad conducían al riesgo de recalar en la exterioridad del hecho literario, en la pura atención a la sonoridad y riqueza de los vocablos; y en el virtuosismo, esa actitud que reúne los temas como pretextos para la destreza formal" (1968: 97). 
lo importante es que la situación relatada resulta absolutamente verosímil: se trata, notoriamente, de un relato creíble, porque en el contexto de las primeras décadas del siglo xx en Buenos Aires, las buenas maneras en materia de lenguaje resultaban absolutamente refractarias respecto de las formas populares, incluso lunfardas, utilizadas por el autor de Los siete locos para redactar esa columna diaria a la que seguían con apasionado interés los numerosos lectores de El Mundo (2003: 177).

La reflexión del escritor evidencia su conciencia respecto del contexto cultural y del uso lingüístico elegido diferenciándose de las posiciones oficiales y, al mismo tiempo, polemiza con ellas. La correspondencia entre el lenguaje y el lector no resulta un dato menor ya que este cronista construye sus aguafuertes a partir de la escenificación del diálogo constante con ellos: la ficcionalización de esas palabras que le hacen llegar por cartas o que escucha por ahí devienen una glosa de las opiniones del pueblo.

No sólo la elección léxica sino también la forma (la brevedad de los párrafos así como la segmentación por subtítulos) constituyen indicios de la orientación popular de su escritura. María Pía López observa que "su postulado idioma proviene del elogio de lo orillero y está escrito en prosa de combate" (López 2015: 28). En definitiva, lo plebeyo en Roberto Arlt supone la elección de una temática al tiempo que la renovación del lenguaje periodístico a partir de la incrustación de expresiones del uso corriente de la lengua. A su vez, la elección del término muchachas del título de la antología, proveniente de la jerga tanguera, manifiesta la predilección del autor por lo marginal. Para cerrar esta reflexión, destacamos que lo plebeyo hizo su ingreso a la crónica en tanto que plebeyo, esto es, como expresión vulgar donde lo cotidiano se opone a lo elevado; como símbolo de lo socialmente deslegitimado por su condición de impureza pero capaz de cuestionar el saber académico; como una lengua en uso que fisura la gramática; una prosa de combate sin refinamiento; como el lenguaje coloquial del pueblo que pone en jaque "el castellano" oficializado, para decirlo con palabras de Arlt. Lo plebeyo deviene una literatura entendida como un cross a la mandíbula. 


\section{CONCLUSIONES}

El recorrido por la crónica latinoamericana propuesto, que comprende desde la celebración de la aristocracia del arte característica del modernismo hasta la reivindicación de lo popular a fines de la década del veinte, permitió identificar una serie de hitos fundamentales para una historia literaria y cultural del género. Los paradigmas analizados han organizado las producciones artísticas durante el siglo XX instituyendo lo que denominamos retóricas de la distinción. Se trata de imaginarios que conciben el mundo a través de pares dicotómicos. Tanto en la priorización de lo culto como en la nueva hegemonía de lo popular se evidenció la persistencia de un discurso que operó en términos jerárquicos clasificando sujetos, objetos y prácticas en célebres o plebeyos, nobles o vulgares, letrados o iletrados.

Las crónicas finiseculares sobre divas de la ópera y el teatro vehiculizaron una retórica del divismo y una consagración sociocultural en términos de prestigio artístico ubicando a los artistas en el centro de la escena. Hacia principios del siglo XX, esta aristocracia del talento se reconfiguró en una retórica de la celebridad que supuso una continuidad porque priorizó dicha temática aunque manifestó una notable apertura de los sujetos susceptibles de ingresar a formar parte del fenómeno de la celebridad al no circunscribirse al campo del arte. Ese cambio de paradigma eclipsó al hombre culto (hombre de arte) e hizo ingresar en la escena cultural a un nuevo sujeto: el hombre famoso reconocido públicamente por la singularidad de su vida. En franca oposición a estas estéticas de signo ilustre, en la escritura de los cronistas surgió una retórica de la plebeyez que se expresó a nivel formal, temático y autofigural. La representación de las clases populares en un lenguaje que se mostraba vulgar marcó de ese modo la consolidación de lo plebeyo como objeto literario de la crónica latinoamericana. 
BIBLIOGRAFÍA

ARLT, ROBERTO. El país del río. Aguafuertes y crónicas de Roberto Arlt y Rodolfo Walsh. Paraná: Eduner, 2016.

1969.

sada, 1994.

BASTOS, MARÍA LUISA. "La crónica modernista de Enrique Gómez Carrillo o la función de la trivialidad". Relecturas (1989): 51-73.

BOURDIEU, PIERRE. Razones prácticas. Sobre la teoría de la acción. Barcelona: Anagrama, 1997.

Cansinos Assens, Rafael. "Figura del día". Cosmópolis 8 (1919): 647-648.

COROMINAS, JOAN. Breve diccionario etimológico de la lengua castellana.

Madrid: Gredos, 1961.

DARío, RuBÉn. Los raros. Buenos Aires: Losada, 2011.

- Poesía. Caracas: Biblioteca Ayacucho, 1977.

- Prosas profanas. Buenos Aires: Biblioteca Ayacucho, 1986.

- Teatros. Prosas desconocidas sobre Sarab Bernhardt. Ricar-

do Llopesa (ed.). Alicante: Aitana, 1993.

FofFANI, ENRIQue. "Introducción". La protesta de los cisnes: coloquio so-

bre Cantos de vida y esperanza de Rubén Darío. 1905-2005. Enrique

Foffani (comp.). La Plata: Katatay, 2007.

. "Literatura, cultura, secularización. Una introducción". Con-

troversias de lo moderno. La secularización en la bistoria cultural

latinoamericana. Enrique Foffani (ed.). La Plata: Katatay, 2010.

Gómez CARrillo, Enrique. Entre encajes, Barcelona: Casa Editorial Sopina, 1909.

. El libro de las mujeres. Madrid: Mundo Latino, 1919.

- Diccionario ideológico para facilitar el trabajo literario y

enriquecer el estilo. Madrid: Renacimiento, 1925.

Groussac, Paul. Viaje intelectual. Impresiones de naturaleza y arte I.

Madrid: Librería General de Victoriano Suárez, 1904. 
GuTiÉRREZ, ALICIA. Las prácticas sociales: una introducción a Pierre Bourdieu. Buenos Aires: Ferreyra, 2005.

GutiérReZ Girardot, RAFAel. Modernismo. México: FCE, 2004.

HABERMAS, JürGEn. "La modernidad, un proyecto incompleto". La posmodernidad. H. Foster (ed.). Barcelona: Kairós, 1983.

LÓPEZ, MARÍA PíA. "A los golpes". Diez aguafuertes comentadas de Roberto Arlt. Buenos Aires: Eufyl, 2015.

Ludmer, Josefina. El cuerpo de delito. Un manual. Buenos Aires: Eterna Cadencia, 2011.

MoRIn, EDGar. Las estrellas del cine. Buenos Aires: Eudeba, 1966.

PRIETO, ADOLFO. Diccionario básico de la literatura argentina. Buenos Aires: CEAL, 1968.

Rama, Ángel. "Prólogo". Rubén Darío. Poesía. Caracas: Biblioteca Ayacucho, 1986.

RETAMOSO, RoBERTO. "Lenguaje y escritura en Roberto Arlt". La trama de la comunicación 8 (2003): 177-180.

SAÍTTA, SYLVIA. "Prólogo". Roberto Arlt, Aguafuertes porteñas: cultura y política. Buenos Aires: Losada, 1994.

SoIZA ReILly, JuAn José. Cien hombres célebres. Buenos Aires: Maucci, 1909.

\section{Maucci, 1911.}

Suárez Urtubey, Paola. "Estudio preliminar". Paul Groussac. Críticas sobre música. Buenos Aires: Biblioteca Nacional, 2007.

SzIR, SANDRA. "Reportaje documental, régimen visual y fotoperiodismo. La ilustración de noticias en la prensa periódica en Buenos Aires (18501910)". Caiana 3 (2013): 1-16.

Terranova, Juan. "El escritor perdido". La ciudad de los locos de Juan José de Soiza Reilly. Buenos Aires: Adriana Hidalgo, 2006.

-Viú AdAgio, Julieta. "La emergencia de las divas en el campo cultural latinoamericano: representaciones artísticas en la crónica modernista". Culturas 13. Debates y perspectivas de un mundo en cambio. Santa Fe: Universidad Nacional del Litoral, 2019. 